\title{
Stress of dynamic loaded protection cab ROPS of truck
}

\author{
Ladislav Ševčík ${ }^{1}$, Ludvík Prášil ${ }^{1}$ \\ ${ }^{1}$ Technical University of Liberec, Dept. of Machine design, Studentská 2, 46117 Liberec 1, Czech Rep.
}

\begin{abstract}
The paper describes the design geometry, calculate deformation, deformation energy and stress safety of extended hydraulically lifted ROPS frame lorry TATRA by FEM according to Australian Standard AS 2294.2-1997 Earth-moving machinery-Protective Structures, Part 2: Laboratory tests and performance requirements for roll-over protective structures and by international Standard ISO 3471: 2008 (E) for the proposed design solution.
\end{abstract}

\section{Introduction}

The aim of the study was to investigate the protective structure of the cab of a truck TATRA $8 \times 8$ to cater for Australian standards. Suggest a change ROPS a proposal verify calculations deformation, stress and energy loss when objects falling on the car cabin. The car is built into mining operations and large excavators an object may fall on a passing truck.

\section{The values specified for the design and calculations ROPS}

The input data and documents geometry was shaped contours cabin, which was carried out according to the design of the safety of prolonged ROPS frame see Figure 1 front view of the cab cover ROPS and Figure 2 lateral view of the cab cover ROPS with off-road truck TATRA $8 \times 8$. It was made of closed profiles $80 \times 80 \times 8$. Design was made in program AutoDESK INVERTOR. Furthermore, the maximum values were given static forces onerous safety ROPS acting in a direction lateral, longitudinal and vertical direction and in the lateral effects of kinetic energy, viz. the table 1, calculated in accordance with Australian Standard AS 2294.2-1997 and international standards ISO 3471: 2008 (E), and the material elements of design was use the unalloyed structural steel designation by CSN 11523 (or ST 52).

The main dimensions of safety frame, the size of the forces and their sphere of activity are the same for all admissible solutions of the protective frame. Location of protective beams is given by norm. The only difference is the size of the square or rectangular cross-section thinwalled closed profiles. Thin square profiles can be reinforced by flat rods with dimensions $80 \times 12 \times 1000 \mathrm{~mm}$. For the following design and calculation must be observed.

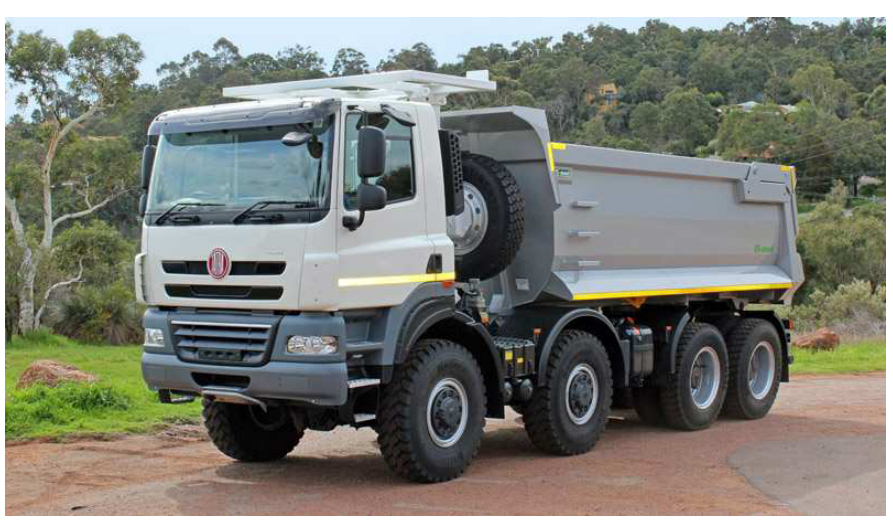

Figure 1. Front view of the cab cover ROPS. [2]

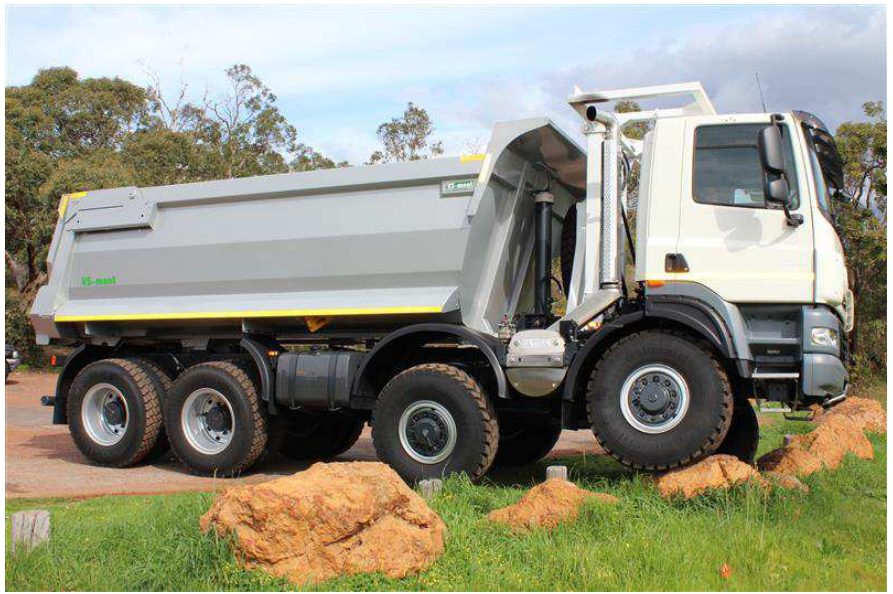

Figure 2. Lateral view of the cab cover ROPS [2].

Orientation of the model in a rectangular coordinate system of safety frame:

$\mathrm{x}$ axis - the direction of the lateral (lateral) forces 
$y$ axis - the direction of the longitudinal force (against cavalry)

$\mathrm{z}$ axis - direction vertical forces

In Table 1 are displayed the value of forces acting in different directions of the coordinate system.

Table 1. The value of forces acting in different directions of the coordinate system.

\begin{tabular}{|l|c|l|c|}
\hline Direction & $x$ (lateral) & $\begin{array}{l}y \\
\text { (longitud } \\
\text { inal) }\end{array}$ & $z$ (vertical) \\
\hline Force $^{*)}$ & $\begin{array}{c}\mathrm{F}_{2} \equiv \mathrm{F}_{\mathrm{x}}= \\
+105778 \\
\mathrm{~N}\end{array}$ & $\begin{array}{c}\mathrm{F}_{3} \equiv \mathrm{F}_{\mathrm{y}}= \\
-84630 \\
\mathrm{~N}\end{array}$ & $\begin{array}{c}\mathrm{F}_{1} \equiv \mathrm{F}_{\mathrm{z}}=- \\
235320 \mathrm{~N}\end{array}$ \\
\hline Energy $^{*}$ & $\begin{array}{c}\mathrm{U}_{2} \equiv \mathrm{U}_{\mathrm{x}}= \\
18839 \mathrm{~J}\end{array}$ & - & - \\
\hline
\end{tabular}

*) Values of all forces and energies in the direction of the lateral were calculated weight of the machine $\mathrm{M}=$ $12,000 \mathrm{~kg}$ according to Australian Standard AS 2294.21997, Tab. 1 - The equation for calculating the forces and energy (Force and energy equations), line 7) Rigid frame machines -only for ROPS (Rigid frame dumpers - ROPS only option) and the International Standard ISO 3471: $2008(\mathrm{E})$.

The design of the protective frame allows its adjustment in two positions. At work, movement position the frame is secured by two pins whose movement is derived from the linear hydraulic motors see. in Figure 3.

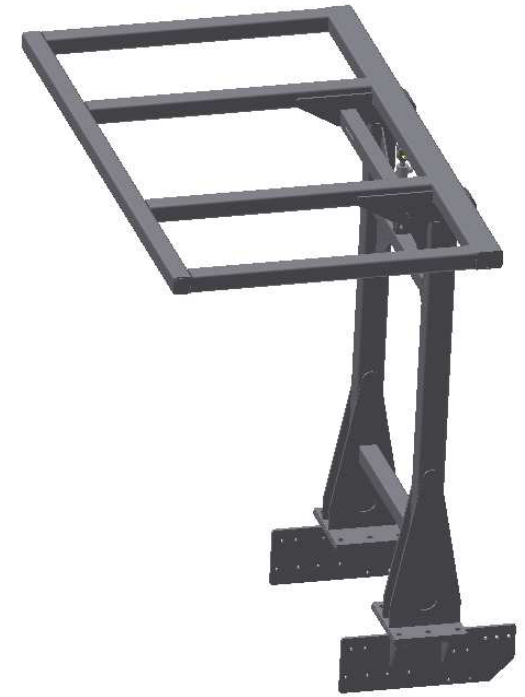
ROPS.

Figure 3. Movement position the frame of the cab cover

For any corrections and adjustments to the car, changing unlocks the pins and turning to see the service position see Figure 4.

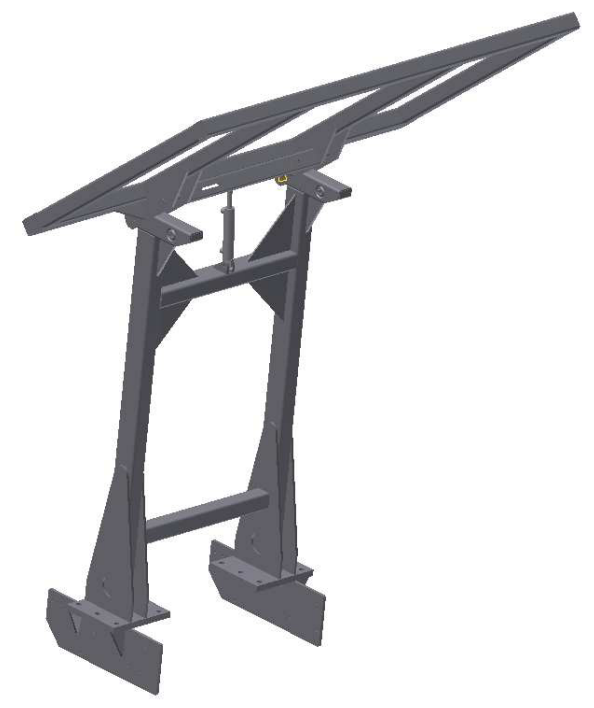

Figure 4. Lateral view of the cab cover ROPS

The boundary conditions for the calculation are shown in Figure 4. The figure shows the forces acting according to the standard. Cross member is only auxiliary and represents a testing device that distributes the load according to all stringers evenly. Protection ROBS is rigidly fixed to the frame of TATRA truck.

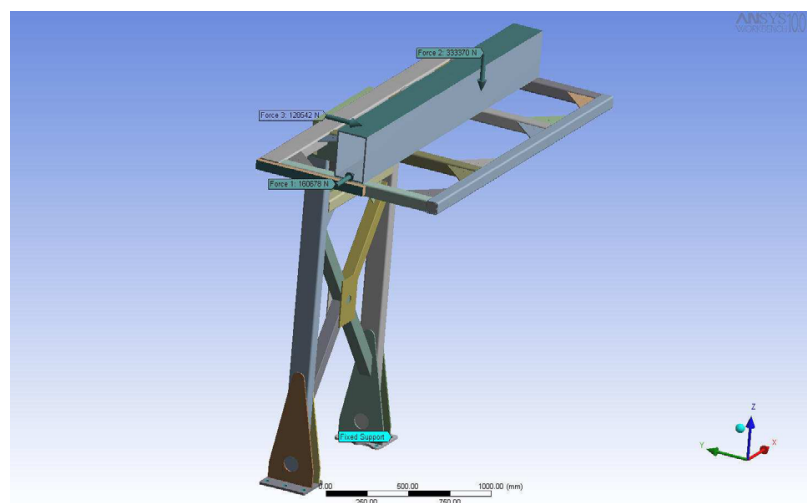

Figure 4. Raised position the frame of the cab cover ROPS.

\section{Calculation of strains and stresses}

Assuming perfect penetration welds the parts connected to the entire construction simplified so that the load is transferred only sections of the work pieces structure, ie. it is not considered material located outside the weld these sections. This simplification is to be done and it can be assumed that significantly affect the results of calculations. FEM calculations are performed for the material constants: modulus of elasticity $\mathrm{E}=200 \mathrm{GPa}$ and Poisson's ratio $\mu=0.3$.

Strains and stresses were calculated for lonely forces amid distributors load (distributors) located:

- For lateral loads in a direction $(+x)$ (lateral load) on the side beam of the frame, the distributor has a length of 
$66.6 \%$ of the distance (L) between the outer front and rear lateral of the upper rectangular frame ROPS and is positioned according to a distance of $1 / 3 \mathrm{~L}$ from the rear lateral of the upper rectangular frame ROPS.

For longitudinal load in the direction of travel (s) (Longitudinal load) in the middle on the rear frame beam width distributor is max. $80 \%$ of the distance (W) between the outer left and right sides of the upper rectangular frame ROPS

For the vertical load in the axial direction (z) (vertical load) in the middle of the vertical load beam (not part of the frame ROPS, see. Figure 4) located midway between the front and rear outer side of the upper rectangular frame ROPS.

On color maps are shown the calculated values of deformation (displacement) and equivalent (reduced) stress by $\mathrm{HMH}$, Figure 5-10. On the color scale is assigned to each color range of strains and stresses. Places where the stress exceeds $500 \mathrm{MPa}$ is colored deep red. These are eg. space boundary conditions of load and sudden transitions. In terms of stress are the most unfavorable values at the connection profiles and corner elements, where there (without considering welds) a sudden change in shape. In these places it is a local (local) peak stresses that causes plastic deformation in a small volume of material and will not affect the resistance to static cross-section or a single load. In these places it is necessary to read the values calculated stress at a reasonable distance from their connections (about two to three times the thickness of the respective structural member).

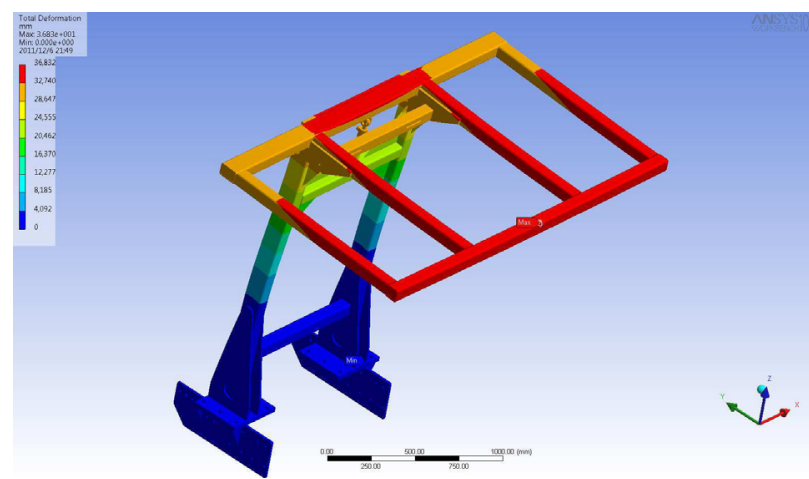

Figure 5. Deformation of ROBS - longitudinal direction.

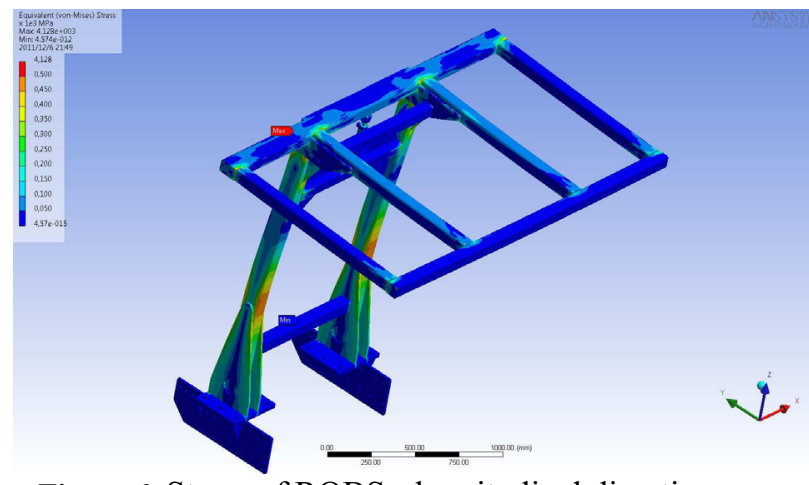

Figure 6. Stress of ROBS - longitudinal direction.

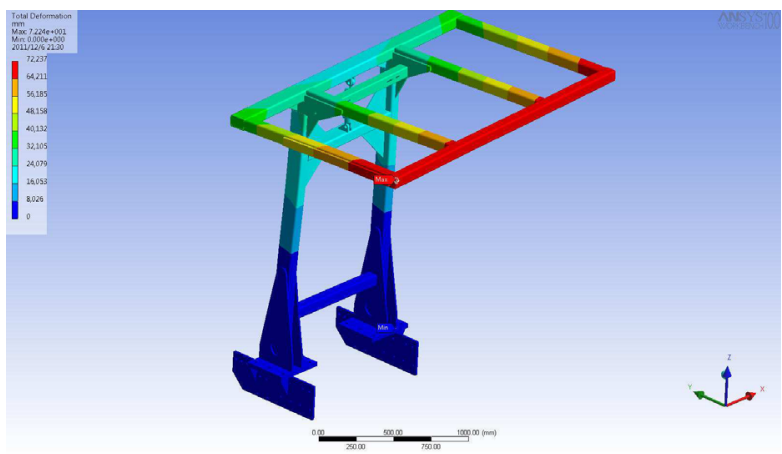

Figure 7. Deformation of ROBS - lateral direction.

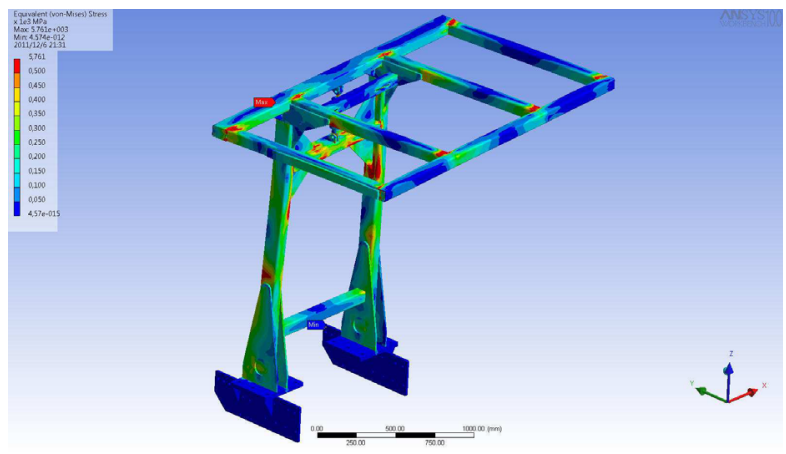

Figure 8. Stress of ROBS - lateral direction.

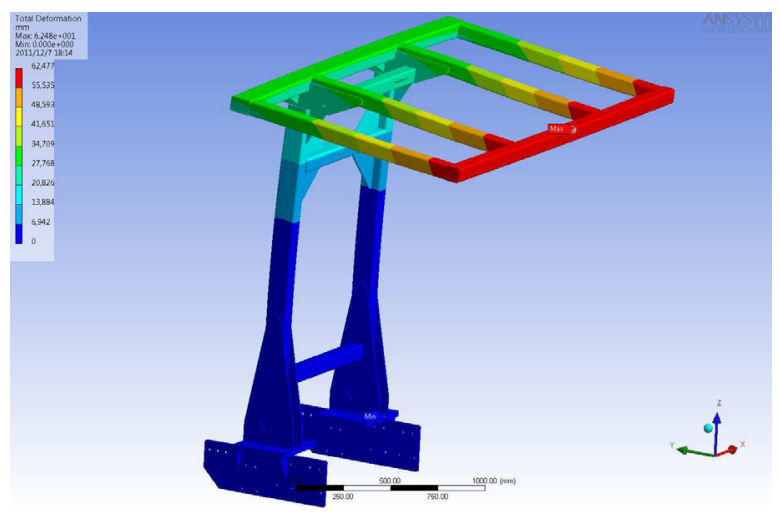

Figure 9. Deformation of ROBS - vertical direction.

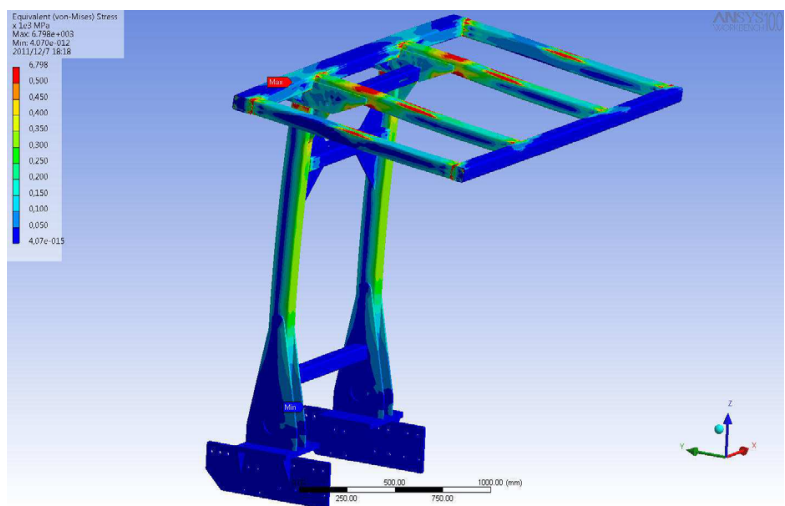

Figure 10. Stress of ROBS - vertical direction.

Evaluation of energy absorption will be considered according to the mechanical energy expended on its deformation in bend - mechanical energy is determined by the following equation [1]: 


$$
U=\int_{x_{1}}^{x_{2}} F(x) d x
$$

In the preceding formula represents:

$\mathrm{U}$ - mechanical energy $[\mathrm{J}]$

$\mathrm{F}(\mathrm{x})$ - function of the force-deformation of the ROPS [N] $\mathrm{x}$ - deformation of test [m]

The energy calculation was performed on elastoplastic model, Figure 11,12.

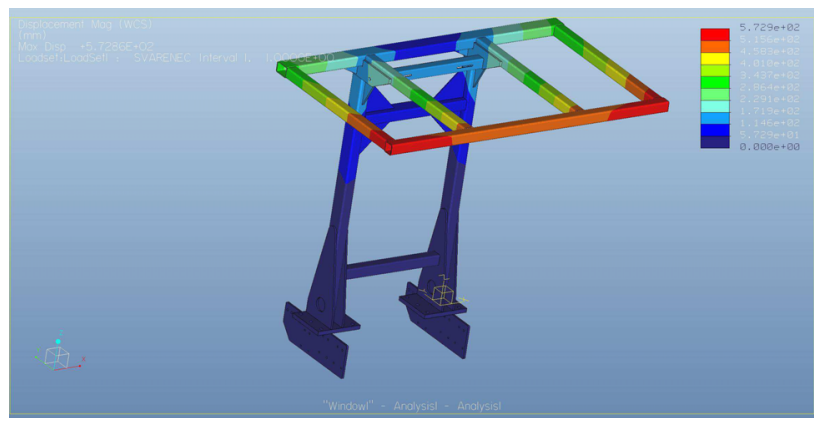

Figure 11. Deformation of ROBS - lateral direction, elastoplastic model.

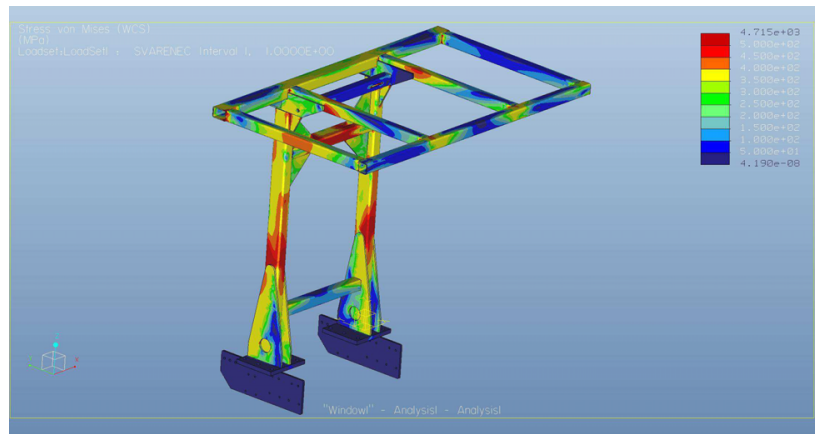

Figure 12. Stress of ROBS - lateral direction, elastoplastic model.

\section{Conclusion}

The resulting of stress and deformation for all variants of the loading are shown in the following Table 2. The modified structure of the safety bracket (third variant) achieved a reduction of the overall deformation in a lateral load force and lateral energy, viz. in Table 2.

Table 2 .: Deformation and stress ROPS in spatial transformation structures.

\begin{tabular}{|c|c|c|c|}
\hline & $\begin{array}{l}\text { Applicati } \\
\text { on of the } \\
\text { force and } \\
\left.\text { energy }{ }^{*}\right)\end{array}$ & $\begin{array}{c}\text { Deformat } \\
\text { ion of } \\
\text { variant } \\
\text { th. } 3 \\
{[\mathrm{~mm}]}\end{array}$ & $\begin{array}{l}\text { Stress of } \\
\text { variant } \\
\text { th. } 8 \\
{[\mathrm{MPa}]}\end{array}$ \\
\hline \multirow{3}{*}{$\begin{array}{c}\text { Max. } \\
\text { deformace } \\
/ \mathrm{mm} /\end{array}$} & vertical & 36,40 & 4100 \\
\hline & lateral & 72,54 & 5700 \\
\hline & $\begin{array}{l}\text { longitudi } \\
\text { nal }\end{array}$ & 62,82 & 6800 \\
\hline $\begin{array}{l}\text { Deformace } \\
\left.{ }^{* *}\right) / \mathrm{mm} /\end{array}$ & lateral $\left.^{*}\right)$ & 573 & 4710 \\
\hline
\end{tabular}

*) After reaching the yield strength of said calculation steps in the elasto-plastic deformation of $10 \mathrm{x}$ lower elastic modulus value, i.e. $\mathrm{E}_{\mathrm{e}-\mathrm{pl}}=20 \mathrm{GPa}$

**) In terms of deformation is in the middle of distributors, ie. when a force corresponding to the calculated value of lateral energy.

The sponsor performed on the recommendation of the investigator changes and process third structural variant of the frame. The calculation results show that by modifying the original design (Option 3) reinforcement flange square thin-walled profile $80 \times 80 \times 6 \mathrm{~mm}$ flat bar dimensions $12 \times 80 \times 1000 \mathrm{~mm}$ achieved a reduction of distortions in the vertical direction by $28.3 \%$ and in the lateral direction by $18 \%$.

By reinforcing the structure of the safety frame was also achieved a reduction of the equivalent stresses in the most loaded cross-sections of the structure. This state is already apparent by simply comparing images that show stress in the same manner load.

In terms of stress are the most unfavorable values particularly at the connection profiles and corner elements, where there is (without considering welds) a sudden change in shape. In these places increased local operating voltage that causes plastic deformation in a small volume of material cross section, so there is a failure in the static or single dose loading. In these places it is necessary to read the values calculated stresses within a reasonable distance of the connection profiles (about two to three times the thickness of the respective structural member).

Based on measured values of deformation and overall stress of prolonged construction safety, hydraulically lifted is ROPS frame. It is clear that not considered at maximum load, according to the standards laid down by AS 2294.2 - 1997 and ISO 3741: 2008 (E) the total destruction of the safety bars.

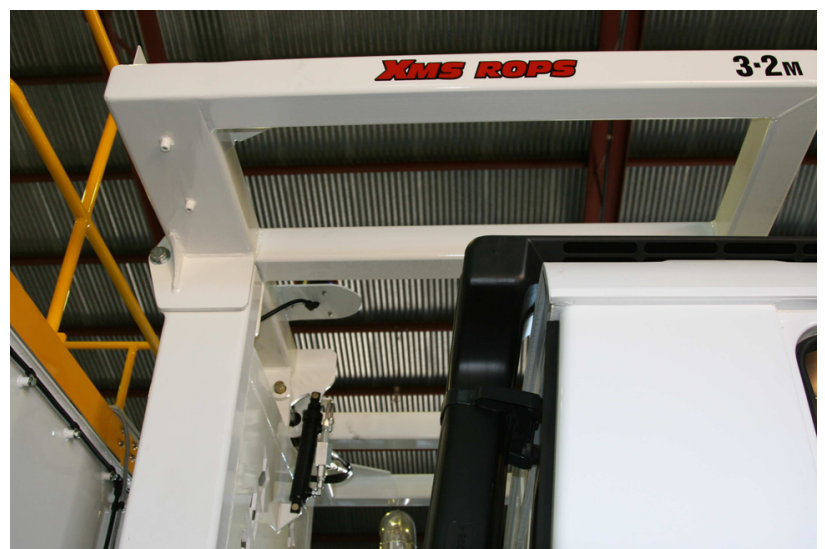

Figure 13. Protective equipment installation ROPS cab truck.

\section{References}

1. Malik L., Medvecky S., Casti a mechanismy strojov; TU Zilina, January 2004.

2. Information on http://www.tatra.cz/ospolecnosti/tisk-a-media/aktualne/tatraphoenix-aplikace-pro-tezarsky-prumysl/ 